\title{
Comparative Performance of Line Probe Assay (Version 2) and Xpert MTB/RIF Assay for Early Diagnosis of Rifampicin-Resistant Pulmonary Tuberculosis
}

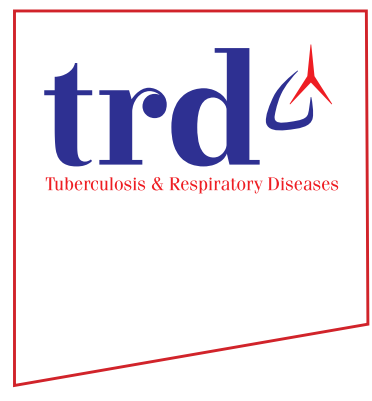

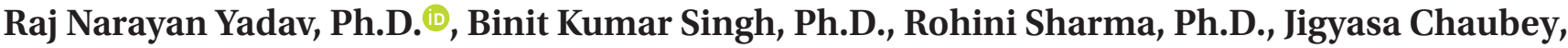 \\ Ph.D., Sanjeev Sinha, M.D. and Pankaj Jorwal, M.D. \\ Department of Medicine, All India Institute of Medical Sciences, New Delhi, India
}

Background: The emergence of drug-resistant tuberculosis (TB), is a major menace to cast off TB worldwide. Line probe assay (LPA; GenoType MTBDRplus ver. 2) and Xpert MTB/RIF assays are two rapid molecular TB detection/diagnostic tests. To compare the performance of LPA and Xpert MTB/RIF assay for early diagnosis of rifampicin-resistant (RR) TB in acid-fast bacillus (AFB) smear-positive and negative sputum samples.

Methods: A total 576 presumptive AFB patients were selected and subjected to AFB microscopy, Xpert MTB/RIF assay and recent version of LPA (GenoType MTBDRplus assay version 2) tests directly on sputum samples. Results were compared with phenotypic culture and drug susceptibility testing (DST). DNA sequencing was performed with rpoB gene for samples with discordant rifampicin susceptibility results.

Results: Among culture-positive samples, Xpert MTB/RIF assay detected Mycobacterium tuberculosis (Mtb) in 97.3\% (364/374) of AFB smear-positive samples and 76.5\% (13/17) among smear-negative samples, and the corresponding values for LPA test (valid results with $M t b$ control band) were $97.9 \%$ (366/374) and 58.8\% (10/17), respectively. For detection of RR among Mtb positive molecular results, the sensitivity of Xpert MTB/RIF assay and LPA (after resolving discordant phenotypic DST results with DNA sequencing) were found to be $96 \%$ and $99 \%$, respectively. Whereas, specificity of both test for detecting RR were found to be $99 \%$.

Conclusion: We conclude that although Xpert MTB/RIF assay is comparatively superior to LPA in detecting $M t b$ among AFB smear-negative pulmonary TB. However, both tests are equally efficient in early diagnosis of AFB smear-positive presumptive RR-TB patients.

Keywords: Multidrug-Resistant Tuberculosis; Mycobacterium tuberculosis Complex; Nontuberculous Mycobacteria; Mutation

Address for correspondence: Pankaj Jorwal, M.D.

Department of Medicine, All India Institute of Medical Sciences, Room Number 3070, 3rd Floor, Teaching Block, New Delhi 110029, India

Phone: 91-011-2659-4001, Fax: 91-011-2659-6690, E-mail: pankajjorwal.aiims@gmail.com

Received: Dec. 31, 2020, Revised: Feb. 6, 2021, Accepted: Mar. 3, 2021, Published online: Mar. 3, 2021

@(t) is identical to the Creative Commons Attribution Non-Commercial License (http://creativecommons.org/licenses/by-nc/4.0/). 


\section{Introduction}

Tuberculosis (TB) remains a significant cause for death worldwide and is the leading cause of death from one infective agent, ranking on top of human immunodeficiency virus (HIV). Globally, in 2018, about ten million people were affected by $\mathrm{TB}$, resulting in 1.3 million deaths among HIV-negative individuals. Drug-resistant TB poses an additional intense challenge, with 484,000 incident cases of multidrug-resistant tuberculosis (MDR-TB). Globally, India along with China and Russian-Federation, contributed about $50 \%$ of total MDR/ rifampicin-resistant (RR)-TB cases ${ }^{1}$.

Early diagnosis of TB, and universal drug susceptibility testing (DST), is the vital element within the machinery of TB control, and thereby very important facet of End TB Strategy². Acid-fast bacilli (AFB) smear microscopy is the most commonly used diagnostic tool for the detection of TB in high burden countries. However, its sensitivity was only $46 \%$ to $63 \%$ when compared against culture, and further decreases in patients with HIV co-infection ${ }^{3,4}$. A conventional culturebased (phenotypic) approach is still considered as 'gold standard,' but it is time-consuming and takes around two to three months for the identification and DST of Mycobacterium tuberculosis (Mtb). To unravel these challenge, a serious push has been given to rapid nucleic acid amplification test (NAAT) based molecular tests like line probe assay (LPA) (GenoType MTBDRplus, Hain Lifescience, Nehren, Germany) and Xpert MTB/RIF assay (Cepheid, Sunnyvale, CA, USA). The LPA (version 1) used to detect $M t b$ and at the same time gave status of rifampicin (RIF) and isoniazid (INH) resistance in sputum samples ${ }^{5}$. The test is appropriate for rapid screening of MDRTB patients but it is recommended in only AFB smear-positive sputum sample because unacceptable performance negated the utilization of this assay in AFB smear-negative samples ${ }^{6}$. Now, a new modified version (GenoType MTBDRplus version 2) of the LPA has been introduced which boasts of its increased performance but there are limited studies regarding its comparative performance with other NAAT-based test. The Xpert MTB/RIF assay was also recommended for rapid and simultaneous detection of $M t b$ and RIF susceptibility ${ }^{7}$; however, optimal detection of AFB smear-negative patient still remains challenging. The aim of present study was to compare the diagnostic performance of GenoType MTBDRplus (version 2) and Xpert MTB/RIF assay in both smear-negative and smearpositive, sputum samples.

\section{Materials and Methods}

\section{Ethical approval}

The study was approved by the Institute Ethics Committee (RT-28/01.06.2012) of All India Institute of Medical Sciences
(AIIMS), New Delhi, India. Informed consent was taken from each patient.

\section{Study subjects}

The patients having previous history of pulmonary TB were recruited from various districts of Delhi and medical outpatient department of AIIMS, New Delhi during December 2013 to October 2015. All mycobacterial laboratory tests were carried out at the accredited Intermediate Reference Laboratory (IRL) of the Department of Medicine, AIIMS, New Delhi. For every patient, two sputum samples (spot and morning) were collected in observance with standard protocol. Both samples were subjected to routine diagnostic test of AFB smear microscopy and solid culture (Lowenstein-Jensen [L-J] media). However, single sample was processed for Xpert MTB/RIF assay, LPA, and liquid culture using BACTEC MGIT 960 system (Becton Dickinson, Sparks, MD, USA). Phenotypic DST was performed only when culture became $M t b$ positive. Mycobacterial growth on any media (solid or liquid) was considered as positive.

\section{Laboratory investigations}

The sputum samples were processed in a bio-safety level (BSL)-3 laboratory. Samples were decontaminated by N-acetyl-L-cysteine with sodium hydroxide (NALC-NaOH) method. Subsequently, the sediments were mixed $1.5 \mathrm{~mL}$ phosphate buffer (sterile) having pH 6.8 and two slopes of L-J medium were inoculated with each decontaminated sample.

\section{Liquid culture using BACTEC MGIT 960}

Liquid culture was performed with $500 \mu \mathrm{L}$ decontaminated samples by BACTEC MGIT 960 instrument. The 7H9 liquid media tube provided by manufacturers was supplemented with growth supplement and PANTA as per manufacturer instructions and incubated in the instrument. Tubes flagged as positive by the instrument were examined visually for mycobacterial growth and were subjected to Zeihl-Neelsen staining to confirm the presence of AFB, and immunochromatographic test using SD BIOLOINE TB Ag MPT64 KIT (SD, Standard Diagnostics, Suwon, Korea). Every culture growth was inoculated on brain heart infusion agar media for sterility checking. Mycobacterial liquid cultures were subcultured on solid L-J media for phenotypic DST.

\section{Phenotypic drug susceptibility testing}

The phenotypic DST was performed with L-J solid media (economic variant of $1 \%$ proportion method) according to the procedure of National TB Elimination Programme (previously it was Revised National Tuberculosis Control Programme $)^{8}$. 
Drug concentrations of RIF and INH used in the test were 40 $\mu \mathrm{g} / \mathrm{mL}$ and $0.2 \mu \mathrm{g} / \mathrm{mL}$, respectively. All isolates were identified as $M t b$ by their growth rate in culture medium, AFB microscopy, morphology of mycobacterial colony on solid medium, and inability to grow on $p$-nitrobenzoic acid $(500 \mu \mathrm{g} / \mathrm{mL})$ containing solid L-J media.

\section{Genotypic drug susceptibility testing}

The Genotypic DST was performed by the GenoType MTBDRplus (version 2) LPA and Xpert MTB/RIF assay.

\section{1) GenoType MTBDRplus LPA}

The GenoType MTBDRplus (version 2) LPA was performed (direct) according to the manufacturer's (Hain Lifescience) instructions. Mycobacterial DNA was extracted using GenoLyse' kit (Hain Lifescience). Polymerase chain reaction (PCR) amplification was performed with amplification mixture (AMA and AM-B) provided with company kit. Hybridization was performed with the automatic machine (GT blot) according to manufacturer manual. After hybridization and washing, strips were removed, fixed on paper and results were interpreted as per manufacturers instructions ${ }^{9}$.

\section{2) Xpert MTB/RIF assay}

Xpert MTB/RIF assay instrument was installed with continuous power supply backup. Onsite training was performed and proficiency testing was conducted with previously characterized mycobacterial culture growth and sputum samples before starting the work. About $2 \mathrm{~mL}$ sample reagent (provided with cartridge) was added to $1 \mathrm{~mL}$ of sputum sample in a falcon tube and slowly vortex twice during 15-minute period at room temperature. Now $2 \mathrm{~mL}$ of this inactivated sample was transferred to the test cartridge (G4 version). The cartridges were inserted into the test platform of the machine. The electronic result output was sent directly to the computer (lap top).

\section{DNA sequencing}

DNA sequencing was carried out for discrepant RIF susceptibility testing results with ABI Prism 3130 genetic analyzer (Applied Biosystem) and BigDye Terminator version 3.1 cycle sequencing kit (Applied Biosystems and Hitachi, Ltd., Carlsbad, CA, USA). DNA was extracted directly from sputum samples using GenoLyse kit (Hain Lifescience). A 305-bp band of гроB gene covering 81-bp rifampicin resistant determining region (RRDR) was amplified by PCR with primer sequence described previously ${ }^{10}$.

\section{Statistical analysis}

Stata 12.1 (Stata Corp., College Station, TX, USA) was used

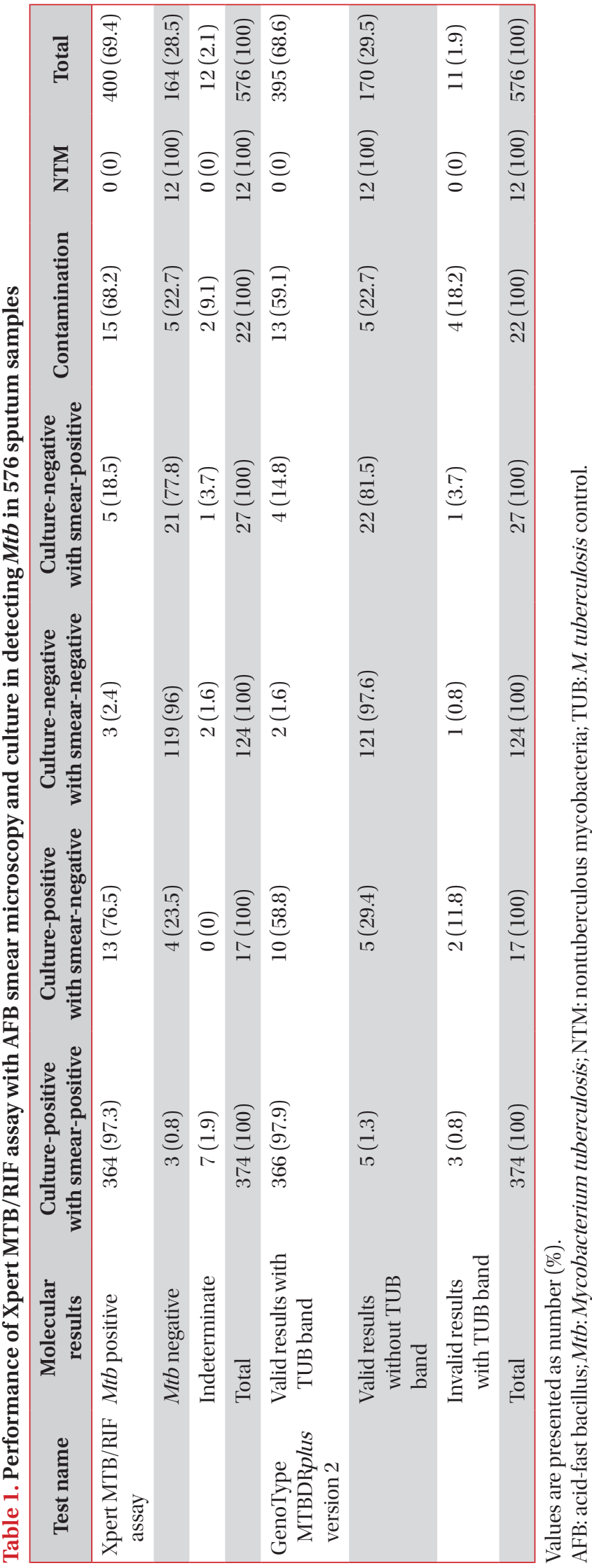


for data presentation. Data were analyzed with frequency (\%) and mean (standard deviation). Sensitivity, specificity, positive predictive value, negative predictive value was determined with $95 \%$ confidence intervals. The software BioEdit and ClustalW were used for analysis of DNA sequencing output and alignment, respectively.

\section{Results}

A total of 576 patients were screened (430 AFB smear-positive and 146 smear-negative) for the study among which 391 were males and 185 were females. Their mean age was 32.9 $( \pm 13$, standard deviation). Culture examination revealed that, $391(67.9 \%)$ were culture-positive, $151(26.2 \%)$ were culturenegative, $22(3.8 \%)$ demonstrated culture contamination and remaining $12(2 \%)$ were found as nontuberculous mycobacteria (NTM). Among these 576 samples, Xpert MTB/RIF assay yielded valid results in $97.9 \%$ (564/576), among which $M t b$ detected in $70.9 \%$ (400/564), $M t b$ not detected in $29.1 \%$ (164/564); and 12 were indeterminate. Whereas, LPA demonstrated valid results in $98.1 \%$ (565/576), among which $69.9 \%$ (395/565) were with M. tuberculosis control (TUB) band and $30.1 \%$ (170/565) didn't show a TUB band; and remaining 11 showed invalid results with the presence of TUB band (Table 1). All NTM were identified as Mtb negative by both molecular tests.

\section{Comparison of Xpert MTB/RIF assay and GenoType MTBDRplus assay for detection of $M t b$}

Among culture-positive with smear-positive samples, Xpert MTB/RIF assay yielded valid results with $M t b$ being detected in $97.3 \%$ (364/374), while LPA delivered valid results with the presence of TUB band in 97.9\% (366/374). Whereas, in samples which were culture-positive and smear-negative results, Xpert MTB/RIF assay detected Mtb in 76.5\% (13/17), and LPA showed valid results, with TUB band, in 58.5\% (10/17) as shown in Table 1. Considering culture results as the gold standard, the comparative performance of both molecular tests is shown in Table 2.

\section{Comparison of Xpert MTB/RIF assay and GenoType MTBDRplus assay against phenotypic DST, for detection of RR-TB}

A total 283 phenotypic DST results were available to compare the performance of Xpert MTB/RIF assay and LPA for detection RR-TB. Phenotypic DST yielded 69 RR-TB (62 MDR$\mathrm{TB}$, and seven RIF resistant/INH sensitive) and 214 RIF sensitive (23 RIF sensitive/INH resistant, 191 sensitive to both RIF and INH) results. Among these 69 phenotypic RR-TB samples, molecular/genotypic test exhibited similar results ( 65 by Xpert MTB/RIF and 67 by LPA). Comparing with phenotypic DST, which is considered as the gold standard, the estimated

Table 2. Overall performance of Xpert MTB/RIF assay and LPA for detecting Mycobacterium tuberculosis from sputum samples with reference to culture

\begin{tabular}{|c|c|c|c|c|c|c|}
\hline \multirow[b]{2}{*}{ Test } & \multicolumn{3}{|c|}{ Sensitivity (\%) } & \multirow[b]{2}{*}{ Specificity (\%) } & \multirow[b]{2}{*}{ PPV (\%) } & \multirow[b]{2}{*}{ NPV (\%) } \\
\hline & $\begin{array}{l}\text { All culture } \\
\text { positive }\end{array}$ & $\begin{array}{l}\text { Culture positive with } \\
\text { smear-positive }\end{array}$ & $\begin{array}{l}\text { Culture positive with } \\
\text { smear-negative }\end{array}$ & & & \\
\hline $\begin{array}{l}\text { Xpert MTB/RIF } \\
\text { assay }\end{array}$ & $98.2(95.3-98.7)$ & $99.2(97.7-99.8)$ & $76.5(50.1-93.2)$ & $94.6(89.6-97.6)$ & $97.9(96.0-98.9)$ & $95.2(90.6-97.7)$ \\
\hline LPA & 97.4 (95.2-98.7) & 98.6 (96.9-99.6) & $66.7(38.4-88.2)$ & $96.0(91.4-98.5)$ & 98.4 (96.6-99.2) & $93.5(88.6-96.3)$ \\
\hline
\end{tabular}

Values in parentheses are presented as $95 \%$ confidence interval. Invalid/indeterminat results were excluded.

LPA: line probe assay; PPV: positive predictive value; NPV: negative predictive value.

Table 3. Performance of Xpert MTB/RIF assay and LPA with phenotypic DST for detecting resistance to rifampicin in 283 culture-positive sputum samples

\begin{tabular}{|c|c|c|c|c|c|c|c|}
\hline \multirow{2}{*}{ Molecular DST } & & \multicolumn{2}{|c|}{ Phenotypic DST } & \multirow{2}{*}{ Sensitivity (\%) } & \multirow{2}{*}{ Specificity (\%) } & \multirow{2}{*}{ PPV (\%) } & \multirow{2}{*}{ NPV (\%) } \\
\hline & & RIF resistant & RIF sensitive & & & & \\
\hline \multirow[t]{2}{*}{ Xpert MTB/RIF assay } & RIF resistant & 65 & 5 & $94(86-98)$ & $98(95-99)$ & $93(85-97)$ & $98(95-99)$ \\
\hline & RIF sensitive & 4 & 209 & & & & \\
\hline \multirow[t]{2}{*}{ LPA (version 2) } & RIF resistant & 67 & 4 & $97(90-100)$ & $98(95-99)$ & $94(86-98)$ & $99(96-100)$ \\
\hline & RIF sensitive & 2 & 210 & & & & \\
\hline
\end{tabular}

Values in parentheses are with $95 \%$ confidence interval.

LPA: line probe assay; DST: drug susceptibility testing; PPV: positive predictive value; NPV: negative predictive value; RIF: rifampicin. 
sensitivity for detection of RR-TB by Xpert MTB/RIF assay and LPA were found to be $94 \%$ (95\% confidence interval [CI], 86-98) and 97\% (95\% CI, 90-100), respectively, whereas both tests showed high specificity of $98 \%$ (95\% CI, 95-99) as detailed in Table 3.

A total of nine samples had discordant RIF susceptibility

Table 4. Discordant rifampicin susceptibility testing results of L-J, LPA, Xpert MTB/RIF assay, and DNA sequencing

\begin{tabular}{|c|c|c|c|c|c|c|c|}
\hline \multirow{2}{*}{$\begin{array}{l}\text { Discordant } \\
\text { cases }\end{array}$} & \multirow{2}{*}{ L-J DST } & \multicolumn{2}{|c|}{ LPA } & \multicolumn{2}{|c|}{ Xpert MTB/RIF assay } & \multicolumn{2}{|c|}{ DNA sequencing } \\
\hline & & Band pattern & Overall results & Failed probe & Overall results & Mutation & Overall results \\
\hline A & S & WT & S & A & $\mathrm{R}$ & Leu511Arg & $\mathrm{R}$ \\
\hline B & S & $\Delta \mathrm{WT} 2,3$ & $\mathrm{R}$ & None & S & None & S \\
\hline $\mathrm{C}$ & $\mathrm{R}$ & WT & S & B & $\mathrm{R}$ & D516Y & $\mathrm{R}$ \\
\hline D & $\mathrm{R}$ & $\Delta \mathrm{WT} 7, \mathrm{MUT} 2 \mathrm{~A}$ & $\mathrm{R}$ & None & S & $\mathrm{H} 526 \mathrm{Y}$ & $\mathrm{R}$ \\
\hline $\mathrm{E}$ & $\mathrm{R}$ & MUT2A & $\mathrm{R}$ & None & S & H526Y & $\mathrm{R}$ \\
\hline $\mathrm{F}$ & $\mathrm{R}$ & $\Delta \mathrm{WT} 8$ & $\mathrm{R}$ & None & S & S531L & $\mathrm{R}$ \\
\hline G & S & $\Delta \mathrm{WT} 8, \mathrm{MUT3}$ & $\mathrm{R}$ & $\mathrm{E}$ & $\mathrm{R}$ & S531L & $\mathrm{R}$ \\
\hline $\mathrm{H}$ & S & $\triangle \mathrm{WT} 8$, MUT3 & $\mathrm{R}$ & $\mathrm{E}$ & $\mathrm{R}$ & None & S \\
\hline I & S & $\Delta \mathrm{WT} 8$ & $\mathrm{R}$ & $\mathrm{E}$ & $\mathrm{R}$ & None & S \\
\hline $\mathrm{J}$ & S & WT & S & E & $\mathrm{R}$ & S531L & $\mathrm{R}$ \\
\hline $\mathrm{K}$ & $\mathrm{R}$ & WT & $\mathrm{S}$ & None & $\mathrm{S}$ & None & $\mathrm{S}$ \\
\hline
\end{tabular}

L-J: Lowenstein-Jensen; LPA: line probe assay; DST: drug susceptibility testing; WT: wild type; S: sensitive; R: resistant; $\Delta$ WT: missing wild type; None: no any probe failed/no mutation.

Table 5. Sequencing analysis of discrepant results for RRDR region of $r p o B$ gene

\begin{tabular}{|c|c|c|}
\hline $\begin{array}{l}\text { Discrepant } \\
\text { cases }\end{array}$ & Codons & Mutation \\
\hline A & $\begin{array}{l}\text { GGCACCAGCCAGCGGAGCCAATTCATGGACCAGAACAACCCGCTGTCGGGGTTGACCACAAGC } \\
\text { GCCGACTGTCGGCGCTG }\end{array}$ & Leu 511Arg \\
\hline B & $\begin{array}{l}\text { GGCACCAGCCAGCTGAGCCAATTCATGGACCAGAACAACCCGCTGTCGGGGTTGACCCACAAGC } \\
\text { GCCGACTGTCGGCGCTG }\end{array}$ & No mutation \\
\hline $\mathrm{C}$ & $\begin{array}{l}\text { GGCACCAGCCAGCTGAGCCAATTCATGTACCAGAACAACCCGCTGTCGGGGTTGACCCACAAGC } \\
\text { GCCGACTGTCGGCGCTG }\end{array}$ & D516Y \\
\hline $\mathrm{D}$ & $\begin{array}{l}\text { GGCACCAGCCAGCTGAGCCAATTCATGGACCAGAACAACCCGCTGTCGGGGTTGACCTACAAGC } \\
\text { GCCGACTGTCGGCGCTG }\end{array}$ & H526Y \\
\hline $\mathrm{E}$ & $\begin{array}{l}\text { GGCACCAGCCAGCTGAGCCAATTCATGGACCAGAACAACCCGCTGTCGGGGTTGACCTACAAGC } \\
\text { GCCGACTGTCGGCGCTG }\end{array}$ & H526Y \\
\hline $\mathrm{F}$ & $\begin{array}{l}\text { GGCACCAGCCAGCTGAGCCAATTCATGTACCAGAACAACCCGCTGTCGGGGTTGACCCACAAGC } \\
\text { GCCGACTGTTGGCGCTG }\end{array}$ & S531L \\
\hline G & $\begin{array}{l}\text { GGCACCAGCCAGCTGAGCCAATTCATGTACCAGAACAACCCGCTGTCGGGGTTGACCCACAAGC } \\
\text { GCCGACTGTTGGCGCTG }\end{array}$ & S531L \\
\hline $\mathrm{H}$ & $\begin{array}{l}\text { GGCACCAGCCAGCTGAGCCAATTCATGGACCAGAACAACCCGCTGTCGGGGTTGACCCACAAGC } \\
\text { GCCGACTGTCGGCGCTG }\end{array}$ & No mutation \\
\hline I & $\begin{array}{l}\text { GGCACCAGCCAGCTGAGCCAATTCATGGACCAGAACAACCCGCTGTCGGGGTTGACCCACAAGC } \\
\text { GCCGACTGTCGGCGCTG }\end{array}$ & No mutation \\
\hline $\mathrm{J}$ & $\begin{array}{l}\text { GGCACCAGCCAGCTGAGCCAATTCATGTACCAGAACAACCCGCTGTCGGGGTTGACCCACAAGC } \\
\text { GCCGACTGTTGGCGCTG }\end{array}$ & S531L \\
\hline $\mathrm{K}$ & $\begin{array}{l}\text { GGCACCAGCCAGCTGAGCCAATTCATGGACCAGAACAACCCGCTGTCGGGGTTGACCCACAAGC } \\
\text { GCCGACTGTCGGCGCTG }\end{array}$ & No mutation \\
\hline
\end{tabular}

The 81-bp rifampicin resistant determining region (RRDR) region includes 27 codons (507-533). Sequences were analyzed with H37Rv sequence. Mutated codons are underlined. Amino acid changes are shown in right side of each aligned sequences. 
results between phenotypic DST and Xpert MTB/RIF assay (Table 4). These were then further analyzed by performing DNA sequencing of RRDR region of $r p o B$ gene. Among four samples (D, E, F, and K) which were RIF resistant by phenotypic DST but sensitive (no probe failure) by Xpert MTB/RIF assay, DNA sequencing (Table 5) revealed mutations in three, involving codons 526 and 531 (H526Y in two and S531L in one) while no mutation was observed in remaining one. Of the five samples (A, G, H, I, J) that were RIF resistant (probe failure) by Xpert MTB/RIF assay and sensitive by phenotypic DST, sequencing demonstrated corresponding mutations in three (Leu511 Arg in one and S531L in two) and no mutations were found in remaining two.

A total of six samples had discordant RIF susceptibility results between LPA and phenotypic DST. Among these, two were RIF resistant by phenotypic DST and sensitive by LPA; DNA sequencing of these samples demonstrated similar result with LPA (no mutation) in one (K) and remaining one (C) was RIF resistant (D516Y mutation). Among four samples that were RIF sensitive by phenotypic DST and resistant by LPA; DNA sequencing demonstrated RIF resistant (S531L mutation) in one and remaining three were observed as sensitive (without mutation). Most common mutation pattern in RIF resistant case was observed due to the failure probe $\mathrm{E}$ in Xpert $\mathrm{MTB} / \mathrm{RIF}$ assay, whereas in LPA corresponding mutation was observed because of missing of WT8 band with the presence of MUT3 band.

Following the resolution of the issue of discordant results with DNA sequencing, the final sensitivity and specificity for Xpert MTB/RIF assay were found to increase to $97 \%$ (95\% CI, 98-99) and 99\% (95\% CI, 82-100) respectively. Whereas, the corresponding values for LPA were found to be $99 \%$ (95\% CI, 92-100) and 99\% (95\% CI, 96-100) respectively, as shown in Table 6.

\section{Discussion}

Over the years, several molecular methods have been de- veloped for direct detection and rapid DST of $M t b$; however, their sensitivity for detection of $M t b$ still is not equal to that of the standard culture method, particularly in smear-negative samples. In the present study the performance of NAAT-based Xpert MTB/RIF assay and recent version of LPA (version 2) were compared against a standard culture reference, after excluding invalid, indeterminate, and culture contamination results. In detecting $M t b$ among smear-positive sputum samples, the Xpert MTB/RIF assay yielded a sensitivity value of $99.2 \%$ with a 95\% CI ranging from 97.7-99.8 while the LPA delivered a sensitivity of $98.6 \%$ with a $95 \%$ CI ranging from 96.9-99.6. These observations showed that both the assays are good and equally efficient with smear-positive sputum samples. In smear-negative samples, the Xpert MTB/RIF assay showed higher yield of $M t b$ (sensitivity, 76.5\%; 95\% CI, 50.1-93.2) when compared to LPA (sensitivity, 66.7\%; 95\% CI, 38.4-88.2). The LPA test demonstrated more $(2 / 17,11.8 \%)$ invalid results (with TUB band) in smear-negative/culture-positive samples, while no indeterminate results was encountered by Xpert MTB/RIF assay in these samples. Hence, it can be suggested that Xpert MTB/RIF assay is more efficient than recent version of LPA in terms of $M t b$ detection among smear-negative samples and hence there is further scope of improvement for LPA in detecting $M t b$ from paucibacillary samples. However, it should be emphasized at this point that, the recent version of LPA used in present study had a significantly higher yield of valid results with TUB band in smear-negative samples, as compared to yield of other studies with the previous version of $\mathrm{LPA}^{11}$, and hence, suggesting superiority of LPA version 2 over LPA version 1.

Sensitivity of Xpert MTB/RIF assay for detecting $M t b$ in this study was comparable with previous studies ${ }^{12,13}$. However, sensitivity of LPA observed in smear-negative samples in the present study with previous reports revealed some inconsistency. While it was lower ( $66.7 \%$ vs. $77.8 \%$ ) as compared to the study led by Meaza et al. ${ }^{14}$, it was higher as compared to many other studies ${ }^{15}$. This inconsistency may be attributed to the difference in patients' profile including HIV status, treatment history of patients, sample size and study population, etc. Both

Table 6. Xpert MTB/RIF assay and LPA comparative results with phenotypic DST after resolving discrepant results with DNA sequencing

\begin{tabular}{|c|c|c|c|c|c|c|c|}
\hline \multirow[t]{2}{*}{ Molecular DST } & & \multicolumn{2}{|c|}{$\begin{array}{l}\text { Phenotypic DST and discrepant } \\
\text { samples with sequencing }\end{array}$} & \multirow{2}{*}{$\begin{array}{c}\text { Sensitivity } \\
(\%)\end{array}$} & \multirow{2}{*}{$\begin{array}{c}\text { Specificity } \\
(\%)\end{array}$} & \multirow[t]{2}{*}{ PPV (\%) } & \multirow[t]{2}{*}{ NPV (\%) } \\
\hline & & RIF resistant & RIF sensitive & & & & \\
\hline \multirow[t]{2}{*}{ Xpert MTB/RIF assay } & RIF resistant & 68 & 2 & $96(88-99)$ & $99(97-100)$ & 97 (90-99) & $99(96-100)$ \\
\hline & RIF sensitive & 3 & 210 & & & & \\
\hline \multirow[t]{2}{*}{ LPA (version 2) } & RIF resistant & 68 & 3 & $99(92-100)$ & $99(96-100)$ & $96(88-99)$ & $100(97-100)$ \\
\hline & RIF sensitive & 1 & 211 & & & & \\
\hline
\end{tabular}

Values in parentheses are with $95 \%$ confidence interval.

LPA: line probe assay; DST: drug susceptibility testing; PPV: positive predictive value; NPV: negative predictive value; RIF: rifampicin. 
tests detected DNA of $M t b$ from culture-negative samples; it may be due to presence of dead bacilli, as the patients were treatment experienced. Identification of $M t b$ DNA from smear and culture-negative samples may be explained as presence of nonviable bacilli which were not detected by AFB smear microscopy.

The results of both the molecular DST were in high agreement with the outcomes of phenotypic DST. The sensitivity of Xpert MTB/RIF assay and LPA were found to be $94 \%$ (95\% CI, 86-98) and 97\% (95\% CI, 90-100), respectively, while specificity of both tests was $98 \%$ for detecting RR-TB. On analysis of the discordant results on the basis of DNA sequencing of RRDR, the overall sensitivity of Xpert MTB/RIF assay and LPA increased to 96\% (95\% CI, 88-99) and 99\% (95\% CI, 92-100), respectively, whereas both tests exhibited high specificity of $99 \%$. Both tests demonstrated a great degree of mutual concordance (279/283) in the detection of RR-TB.

One sample which exhibited RIF resistance in phenotypic DST was contradictorily sensitive in both the molecular tests. However, DNA sequencing of the sample in question did not show any mutation, signifying the possibility of the mutation outside the RRDR region of $r p o B$ gene. Some studies have reported both the molecular tests as having a high degree of sensitivity and specificity in detecting resistance to RIF, and are in agreement with the present study ${ }^{13,15}$. However, in another study, it was inferred that Xpert MTB/RIF assay is suboptimal as compared to LPA for detecting RR-TB ${ }^{16}$. It can be suggested that the reason for such a finding could be that they have selected samples with RIF monoresistant results only and did not include MDR-TB samples.

One of the most challenges in early diagnosis of TB is the microbiological confirmation and production of reliable mycobacterial DST results, from smear-negative/paucibacillary samples. In contrast to the time-consuming conventional diagnostic tests, Xpert MTB/RIF assay is a rapid point-of-care test, yielding results within two hours. It is extensively used for detection of $M t b$ and RIF susceptibility, in samples from extrapulmonary $\mathrm{TB}^{17}$, presumptive pediatric TB, HIV-TB co-infected patients and smear-negative pulmonary TB patients, which generally have a low bacillary load/paucibacillary in nature ${ }^{18}$. The test, which is a based on real-time PCR called cartridgebased nucleic acid amplification test (CBNAAT), is easier to handle ${ }^{19}$, and requires simple infrastructure and lesser human resources in comparison to LPA, thereby making it cost-effective. Recently a battery operated, chip-based molecular diagnostic test called Truenat is developed by MolBio Diagnostics Pvt Ltd Goa, India for rapid detection of TB and RIF resistance, but unlike CBNAAT, it is an open system, not fully automated and is more suitable for primary health care centre ${ }^{20,21}$. One of the main advantages of molecular diagnostic assays is the less chance of cross-contamination; and short turnaround time, leading to early initiation of treatment, thereby curbing further transmission of drug-resistant $\mathrm{TB}^{22}$.
To conclude, present study finds that Xpert MTB/RIF assay to be better than LPA in detecting Mtb among AFB smearnegative samples. However, both tests are equally efficient in early detection of $M t b$ and Rifampicin resistance in sputum smear-positive pulmonary TB patients.

\section{Authors' Contributions}

Conceptualization: Sinha S, Jorwal P, Yadav RN. Methodology: Yadav RN, Singh BK, Sharma R, Chaubey J. Formal analysis: Sinha S, Jorwal P, Yadav RN, Singh BK. Writing - original draft preparation: Jorwal P, Yadav RN, Singh BK. Approval of final manuscript: all authors.

\section{Conflicts of Interest}

No potential conflict of interest relevant to this article was reported.

\section{Acknowledgments}

We are thankful to the staff of Department of Medicine for their help in carrying out this study. Authors acknowledge the support of Foundation for Innovative New Diagnostics (FIND) India for providing logistic support.

\section{Funding}

No funding to declare.

\section{References}

1. World Health Organization. Global tuberculosis report 2019 [Internet]. Geneva: World Health Organization; 2019 [cited 2020 Dec 20]. Available from: https://www.who.int/tb/publications/global_report/en/.

2. Wu Z, Rueda ZV, Li T, Zhang Z, Jiang Y, Sha W, et al. Effect of the Xpert MTB/RIF on the detection of pulmonary tuberculosis cases and rifampicin resistance in Shanghai, China. BMC Infect Dis 2020;20:153.

3. Wright PW, Wallace RJ Jr, Wright NW, Brown BA, Griffith DE. Sensitivity of fluorochrome microscopy for detection of $\mathrm{My}$ cobacterium tuberculosis versus nontuberculous mycobacteria. J Clin Microbiol 1998;36:1046-9.

4. Young DB, Perkins MD, Duncan K, Barry CE 3rd. Confronting the scientific obstacles to global control of tuberculosis. J Clin Invest 2008;118:1255-65.

5. World Health Organization. Molecular line probe assays for 
rapid screening of patients at risk of multi-drug resistant tuberculosis (MDR-TB). Policy statement [Internet]. Geneva: World Health Organization; 2008 [cited 2020 Dec 20]. Available from: https://www.who.int/tb/features_archive/expert_ group_report_june08.pdf.

6. Singh BK, Sharma SK, Sharma R, Sreenivas V, Myneedu VP, Kohli M, et al. Diagnostic utility of a line probe assay for multidrug resistant-TB in smear-negative pulmonary tuberculosis. PLoS One 2017;12:e182988.

7. World Health Organization. Xpert MTB/RIF assay for the diagnosis of pulmonary and extrapulmonary TB in adults and children. Policy update [Internet]. Geneva: World Health Organization; 2013 [cited 2020 Dec 20]. Available from: http:// www.who.int/tb/laboratory/xpert_launchupdate/en/.

8. Central TB Division, Directorate General of Health Services, Ministry of Health and Family Welfare, Government of India. Revised National TB Control Programme: manual of standard operating procedures (SOPs). Culture of $\mathrm{Myco}$ bacterium tuberculosis and drug susceptibility testing on solid medium [Internet]. New Delhi: Ministry of Health and Family Welfare, Government of India; 2009 [cited 2020 Dec 20]. Available from: https://tbcindia.gov.in/WriteReadData/ 1892s/7293794058standard\%20operating\%20procedures\%20 for\%20C\&DST\%20labs.pdf.

9. Crudu V, Stratan E, Romancenco E, Allerheiligen V, Hillemann A, Moraru N. First evaluation of an improved assay for molecular genetic detection of tuberculosis as well as rifampin and isoniazid resistances. J Clin Microbiol 2012;50:1264-9.

10. Williams DL, Waguespack C, Eisenach K, Crawford JT, Portaels F, Salfinger M, et al. Characterization of rifampinresistance in pathogenic mycobacteria. Antimicrob Agents Chemother 1994;38:2380-6.

11. Barnard M, Gey van Pittius NC, van Helden PD, Bosman M, Coetzee G, Warren RM. The diagnostic performance of the GenoType MTBDRplus version 2 line probe assay is equivalent to that of the Xpert MTB/RIF assay. J Clin Microbiol 2012;50:3712-6.

12. Steingart KR, Schiller I, Horne DJ, Pai M, Boehme CC, Dendukuri N. Xpert(R) MTB/RIF assay for pulmonary tuberculosis and rifampicin resistance in adults. Cochrane Database Syst Rev 2014;2014:CD009593.

13. Boehme CC, Nabeta P, Hillemann D, Nicol MP, Shenai S, Krapp F, et al. Rapid molecular detection of tuberculosis and rifampin resistance. N Engl J Med 2010;363:1005-15.
14. Meaza A, Kebede A, Yaregal Z, Dagne Z, Moga S, Yenew B, et al. Evaluation of genotype MTBDRplus VER 2.0 line probe assay for the detection of MDR-TB in smear positive and negative sputum samples. BMC Infect Dis 2017;17:280.

15. Matabane MM, Ismail F, Strydom KA, Onwuegbuna O, Omar $\mathrm{SV}$, Ismail N. Performance evaluation of three commercial molecular assays for the detection of Mycobacterium tuberculosis from clinical specimens in a high TB-HIV-burden setting. BMC Infect Dis 2015;15:508.

16. Rufai SB, Kumar P, Singh A, Prajapati S, Balooni V, Singh S. Comparison of Xpert MTB/RIF with line probe assay for detection of rifampin-monoresistant Mycobacterium tuberculosis. J Clin Microbiol 2014;52:1846-52.

17. Sharma SK, Kohli M, Chaubey J, Yadav RN, Sharma R, Singh BK, et al. Evaluation of Xpert MTB/RIF assay performance in diagnosing extrapulmonary tuberculosis among adults in a tertiary care centre in India. Eur Respir J 2014;44:1090-3.

18. Central TB Division, Directorate General of Health Services, Ministry of Health and Family Welfare, Government of India. Revised National Tuberculosis Control Programme. Technical and operational guidelines for tuberculosis control in India [Internet]. New Delhi: Ministry of Health and Family Welfare, Government of India; 2016 [cited 2020 Dec 20]. Available from: https://bcindia.gov.in/index1.php?page=1\&i pp=10\&lang=1\&level=2\&sublinkid=4573\&lid=3177.

19. Sharma SK, Kohli M, Yadav RN, Chaubey J, Bhasin D, Sreenivas V, et al. Evaluating the diagnostic accuracy of Xpert MTB/RIF assay in pulmonary tuberculosis. PLoS One 2015;10:e0141011.

20. Lee DJ, Kumarasamy N, Resch SC, Sivaramakrishnan GN, Mayer KH, Tripathy S, et al. Rapid, point-of-care diagnosis of tuberculosis with novel Truenat assay: cost-effectiveness analysis for India's public sector. PLoS One 2019;14:e218890.

21. Stop TB Partnership. Practical considerations for implementation of Truenat [Internet]. Geneva: Stop TB Partnership; 2020 [cited 2020 Dec 20]. Available from: http://www.stoptb. org/assets/documents/resources/wd/Practical\%20Considerations\%20for\%20Implementation\%20of\%20Truenat.pdf.

22. Yadav RN, Singh BK, Sharma SK, Sharma R, Soneja M, Sreenivas V, et al. Comparative evaluation of GenoType MTBDRplus line probe assay with solid culture method in early diagnosis of multidrug resistant tuberculosis (MDR-TB) at a tertiary care centre in India. PLoS One 2013;8:e72036. 